\title{
Unified Solution of Coulomb's Earth Pressure for Retaining Wall Expansion and Parameter Sensitivity Analysis
}

\author{
Hengli Wang ${ }^{1,2}$, Zhengsheng Zou ${ }^{1,2, ~ *}$, Jian Liu ${ }^{3}$, and Xinyu Wang ${ }^{1,2}$ \\ ${ }^{1}$ International Joint Research Laboratory of Henan Province for Underground Space Development and Disaster Prevention, Jiaozuo \\ 454003, China \\ ${ }^{2}$ School of civil Engineering, Henan Polytechnic University, Jiaozuo 454003, China \\ ${ }^{3}$ China Railway 16th Bureau Group Co., Ltd., Beijing 100018, China
}

Received 2 March 2021; Accepted 15 May 2021

\begin{abstract}
To reveal the interaction between the retaining wall and the filling behind the wall, considering the friction, the bonding force of the wall-soil interface and the local overload effect, the unified solution of the extended Coulomb's earth pressure was established based on the ultimate equilibrium condition of the sliding wedge behind the wall. Through the calculation examples satisfying Coulomb and Rankine's assumptions, the proposed method was compared with the existing methods, and the influence of wall-soil interface bonding force and load distance was analysed. Results show that the classic Coulomb's earth pressure formula and Rankine's earth pressure formula are the special cases of the formula obtained. The active earth pressure first decreases and then increases with the increase of the wall-soil cohesion when the cohesion of the backfill is large, and increases with the increase of the wall-soil cohesion when the cohesion of the backfill is small. The passive earth pressure increases with the increase of the bonding force between the wall and the backfill. The angle among the active and the passive earth pressures and the wall back normal increases with the increase of the wall-soil bonding force. The conclusions obtained in this study provide a significantly reference to the similar practice.
\end{abstract}

Keywords: Active earth pressure, Passive earth pressure, Wall-soil bonding force, Slip angle, Cohesive

\section{Introduction}

Earth pressure is the interaction force between the retaining wall and the soil behind the wall, which is an important basis for the design of the retaining wall. The classic Rankine's theory and Coulomb's theory are common algorithm for calculating the earth pressure. The classic Rankine's theory assumes that the back of the wall is vertical, smooth and the filling behind the wall is a semi-infinite soil with a horizontal surface. The earth pressure formula is derived based on the filling in the limit equilibrium state. The classic Coulomb's earth pressure theory assumes that the backfill of the wall breaks along the plane of the wall heel, which is derived based on the balance of the sliding wedge body force.

According to actual engineering needs, many scholars continued to supplement and revise the classic theory, expanding the scope of application of the classic earth pressure theory, making it suitable for cohesive fill, local or uniform overload on the fill surface, seismic action, and other complicated situations. Some scholars also consider soil arching effects or study the earth pressure of retaining walls through the method of section method, limit analysis method, plastic analysis method, finite element method, and pseudo-dynamic method. However, the direction of the action of earth pressure is often limited, which leads to the failure to fully consider the interaction between the retaining wall and the filling behind the wall, or there is a certain correlation between the wall and soil parameters, and it is impossible to objectively understand the effect of the parameters.

Based on Coulomb's theory, Motta gave the calculation method of active earth pressure under long-distance overload of cohesionless soil [1]. Paik et al. considered the arching effect in the soil and improved the horizontal plate element method, they proposed a new formula for calculating the active earth pressure of a rigid retaining wall with cohesionless soil [2-4]. Choudhury et al. used the pseudodynamic method and the horizontal plate element method to analyze the soil wedge behind the wall based on the assumption of a plane sliding surface, they proposed a new formula for calculating the earth pressure of a rigid retaining wall of non-cohesive soil [5-6]. Pain et al. studied the sliding stability of the retaining wall under the action of an earthquake, considering the magnification effect of the soil mass, they improved the pseudo-dynamic method and established a calculation formula for the seismic active earth pressure of cohesive soil. Considering the combined effect of the arching effect in the non-cohesive soil and the wallsoil friction, they also established a passive earth pressure calculation method [7-8]. Rajesh and Choudhury proposed a modified pseudo-dynamic method suitable for underwater soil, they established a seismic active earth pressure method for underwater retaining walls [9].

In practical engineering, the backfill behind the walls is mostly cohesive soil. Therefore, it is very important to establish a unified solution of extended Coulomb's earth pressure, which is suitable for many complex situations. 


\section{State of the art}

Santhoshkumar and Ghosh adopted the characteristic method related to the pseudo-dynamic method without setting any failure mechanism, they established a method for calculating the seismic earth pressure of cohesive soil [1013]. Khatri established a method for calculating the seismic passive earth pressure of non-cohesive soils based on the lower limit finite element analysis and using a modified pseudo-dynamic analysis method [14]. Maskar and Madhekar based on the redistribution principle, they obtained the seismic active earth pressure distribution of the cohesive soil [15]. Krabbenhoft used upper and lower finite element limit analysis to derive a series of earth pressure coefficients [16]. Based on the limit equilibrium theory, Gupta and Sawant established a calculation formula for the seismic active earth pressure of a non-cohesive soil retaining wall considering the effect of the soil magnification [17]. Veiskarami et al. used the lower bound analysis method, finite element and linear programming optimization techniques and iterative procedures to establish static and seismic active earth pressure and passive earth pressure methods for anisotropic cohesive soil retaining walls [18].

Since the backfill behind the walls is mostly cohesive soil in practical engineering, some scholars have improved the calculation method of earth pressure. Shukla et al. analyzed the soil wedge behind the vertical wall and established a calculation method for the earth pressure of the cohesive soil retaining wall under the action of an earthquake through the force polygon [19]. Vahedifard et al. considered the negative pore pressure or matrix suction caused by precipitation, they established a calculation method for the active earth pressure of cohesive soil under the condition of unsaturated steady flow [20]. However, these methods do not fully consider the interaction between the retaining wall and the cohesive fill.

However, these methods all assume that the angle between the direction of action of the earth pressure and the normal direction of the wall back is the wall-soil friction angle, which means that the calculated earth pressure is actually only the resultant force of the normal force acting on the wall back and the friction force of the wall-soil interface. The bonding force of the wall-soil interface is not included. Shukla considered the cohesive force of the wallsoil interface and gave the expression of active earth pressure under static and seismic loads, but did not consider the effect of the wall-soil interface friction [21]. The resultant force of earth pressure should include the friction force and bonding force of the wall-soil interface. Peng and Zhu used the horizontal strip method to analyze the soil behind the wall, they derived the calculation formula for the active earth pressure distribution of cohesive soil based on the shear stress reciprocal theorem [22]. Irdmoosa and Shahir studied the soil arching in the backfill of the wall. Considering the friction and bonding force of the wall-soil interface, based on the assumption of principal stress rotation, they also proposed a method for calculating cohesive soil pressure [23-25]. These scholars considered the bonding force of the wall-soil interface, but they assumed that there was a fixed proportionality coefficient between the wall-soil bonding force and the cohesive force of the cohesive fill and there was an associated limitation on the wall-soil bonding force.

In this study, based on the classic Coulomb's earth pressure theory, considering the friction and bonding force between retaining wall and backfill, the cohesion of the filling, the local overload effect, the correlation between the mechanical parameters of wall-soil interface and the mechanical parameters of soil behind the wall not being specified, the unified solution of extended Coulomb's earth pressure was established, which was suitable for many complex situations. The new method was compared with the calculation method established by other scholars, and the influence of wall-soil bonding force, the load action distance on earth pressure and its action direction, slip angle were also analyzed.

The rest of this study is organized as follows. Section 3 presents the proposed method in detail. Section 4 describes the results and discussion, and finally, the conclusions are summarized in Section 5.

\section{Methodology}

\subsection{Passive earth pressure}

According to Coulomb's earth pressure theory, the wall-soil condition is shown in Fig. 1(a). Assuming that the bonding force between wall soil is $c_{\mathrm{w}}$ and the cohesion of filling is $c$, the stress analysis diagram is shown in Fig. 1(b). The shear force (tangential force) on the wall back $\mathrm{AB}$ is

$$
F=\frac{c_{\mathrm{w}} H}{\cos \alpha}+N_{\mathrm{E}} \tan \delta
$$

The shearing force on the slip surface $\mathrm{BC}$ in the filling is

$$
T=\frac{c H \cos (\alpha-\beta)}{\cos \alpha \sin (\theta-\beta)}+N_{\mathrm{R}} \tan \varphi
$$

where $F$ is the tangential force acting on the wall back, which is composed of the bonding and friction force of the wall-soil interface. $N_{\mathrm{E}}$ is the normal force acting on the wall back. $T$ is the tangential force acting on the slip surface, which is composed of the cohesion and friction of the filling. $N_{\mathrm{R}}$ is the normal force acting on the slip surface, $\delta$ is the friction angle of the wall-soil interface, $\varphi$ is the internal friction angle of the filling, and $q$ is the concentration of the projection of the overload on the horizontal plane. The meanings of other symbols are shown in Fig. 1.

It can be seen from Fig. 1 that for the slip soil wedge, there are some relations as follows:

$$
\begin{aligned}
& \overline{A B}=\frac{H}{\cos \alpha} \quad, \quad \overline{A C}=\frac{\overline{A B} \cos (\theta-\alpha)}{\sin (\theta-\beta)}=\frac{H \cos (\theta-\alpha)}{\cos \alpha \sin (\theta-\beta)}, \\
& \overline{B C}=\frac{\overline{A B} \cos (\alpha-\beta)}{\sin (\theta-\beta)}=\frac{H \cos (\alpha-\beta)}{\cos \alpha \sin (\theta-\beta)} .
\end{aligned}
$$

The self-weight of the soil is

$$
\begin{aligned}
W & =\frac{\gamma}{2} \overline{A B} * \overline{A C} \cos (\alpha-\beta) \\
& =\frac{1}{2} \gamma H^{2} \frac{\cos (\theta-\alpha) \cos (\alpha-\beta)}{\cos ^{2} \alpha \sin (\theta-\beta)}
\end{aligned}
$$

The overload on the surface of filling is as follows: 


$$
\begin{aligned}
Q & =q * \overline{A C} \cos \beta-q d \\
& =\frac{q H \cos (\theta-\alpha) \cos \beta}{\cos \alpha \sin (\theta-\beta)}-q d
\end{aligned}
$$

According to the force of the wedge, the balance equations of $X$ and $Y$ direction forces are listed respectively

$$
\begin{aligned}
\sum F_{\mathrm{y}}= & Q+W+F \cos \alpha-N_{\mathrm{E}} \sin \alpha \\
& +T \sin \theta-N_{\mathrm{R}} \cos \theta=0 \\
\sum F_{\mathrm{x}}= & F \sin \alpha+N_{\mathrm{E}} \cos \alpha-T \cos \theta \\
& -N_{\mathrm{R}} \sin \theta=0
\end{aligned}
$$

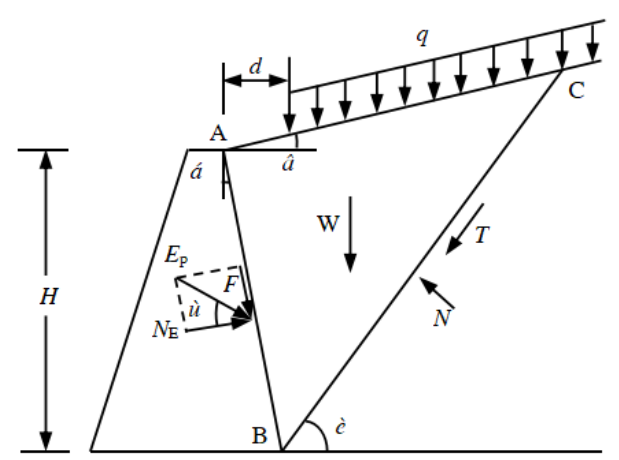

(a) Retaining wall conditions

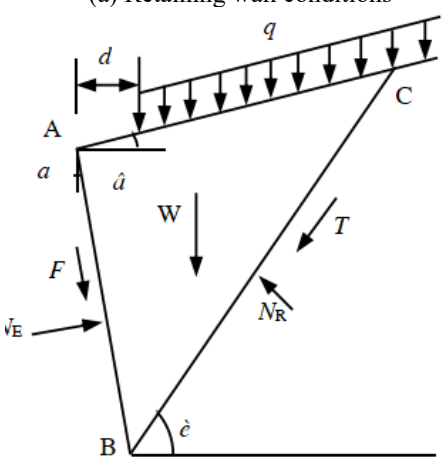

(b) Force on wedge

Fig. 1. Condition of retaining wall and forces on the wedge.

Substituting Eqs. (1) to (4) into the balance Eqs. (5) and (6) to solve them simultaneously, eliminating $N_{\mathrm{R}}$, then get

$$
\begin{aligned}
N_{E}= & \frac{1}{2} \gamma H^{2} K_{\mathrm{p} 1}+q H K_{\mathrm{p} 2}+c H K_{\mathrm{p} 3}+c_{\mathrm{w}} H K_{\mathrm{p} 4} \\
& -q d K_{\mathrm{p} 5}
\end{aligned}
$$

where,

$$
\begin{gathered}
K_{\mathrm{p} 1}=\frac{\cos (\theta-\alpha) \cos (\alpha-\beta) \sin (\varphi+\theta) \cos \delta}{\cos ^{2} \alpha \sin (\theta-\beta) \cos (\delta-\alpha+\varphi+\theta)}, \\
K_{\mathrm{p} 2}=\frac{\cos (\theta-\alpha) \cos \beta \sin (\varphi+\theta) \cos \delta}{\cos \alpha \sin (\theta-\beta) \cos (\delta-\alpha+\varphi+\theta)}, \\
K_{\mathrm{p} 3}=\frac{\cos (\alpha-\beta) \cos \varphi \cos \delta}{\cos \alpha \sin (\theta-\beta) \cos (\delta-\alpha+\varphi+\theta)}, \\
K_{\mathrm{p} 4}=\frac{\sin (\varphi+\theta-\alpha) \cos \delta}{\cos \alpha \cos (\delta-\alpha+\varphi+\theta)}, K_{\mathrm{p} 5}=\frac{\sin (\varphi+\theta) \cos \delta}{\cos (\delta-\alpha+\varphi+\theta)} .
\end{gathered}
$$

Since the normal force $N_{\mathrm{E}}$ is a function of the slip angle $\theta$, there is a minimum value $N_{\mathrm{Ep}}$, so the passive earth pressure $E_{\mathrm{p}}$ is

$$
E_{\mathrm{p}}=\sqrt{F^{2}+N_{\mathrm{Ep}}^{2}}
$$

where, $N_{\mathrm{E}}$ in $F$ calculation formula is replaced by $N_{\mathrm{Ep}}$. The angle between the direction of the passive earth pressure and the normal of the wall back is $\omega_{\mathrm{p}}$ :

$\omega_{\mathrm{p}}=\arctan \frac{F}{N_{\mathrm{Ep}}}=\arctan \frac{\frac{c_{\mathrm{w}} H}{\cos \alpha}+N_{\mathrm{Ep}} \tan \delta}{N_{\mathrm{Ep}}}$

Obviously, $\omega_{\mathrm{p}}>\delta$, and $\omega_{\mathrm{p}}$ varies with $c_{\mathrm{w}}$. However, when $c_{\mathrm{w}}=0, \omega_{\mathrm{p}}=\delta, E_{\mathrm{p}}=N_{\mathrm{Ep}}{ }^{\prime} \cos \delta$. Assuming that the angle between the direction of the earth pressure and the normal of the wall back is the friction angle of the wall-soil, the calculated earth pressure is only the resultant force of the normal force and the friction force, and the effect of the wall-soil bonding force is not correctly considered.

When the filling behind the wall is cohesionless soil $\left(c=0, c_{\mathrm{w}}=0\right)$ and there is no overload effect $(q=0)$, Eq. (7) is

$$
N_{\mathrm{E}}=\frac{1}{2} \gamma H^{2} K_{\mathrm{p} 1}
$$

Since the normal force $N_{\mathrm{E}}$ is a function of the slip angle $\theta$, the explicit expression can be obtained directly by $\mathrm{d} N_{\mathrm{E}} / \mathrm{d} \theta=0$, and substituting Eq. (10) to obtain the minimum value $N_{\mathrm{Ep}}$ expression, and $F=N_{\mathrm{E}_{\mathrm{p}}} \tan \delta$, Therefore, the passive earth pressure is $E_{\mathrm{p}}=\sqrt{F^{2}+N_{\mathrm{Ep}}^{2}}=\frac{1}{2} \gamma H^{2} K_{\mathrm{p}}$.

$$
\text { where, } K_{\mathrm{p}}=\frac{\cos ^{2}(\varphi+\alpha)}{\cos ^{2} \alpha \cos (\alpha-\delta)\left[1-\sqrt{\frac{\sin (\varphi+\delta) \sin (\varphi+\beta)}{\cos (\alpha-\delta) \cos (\alpha-\beta)}}\right]^{2}} \text {. }
$$

If the filling behind the wall is cohesionless soil and there is no overload effect, the formula of the passive earth pressure is equal to the classic Coulomb's formula.

When the back of the wall is vertical and smooth and the filling behind the wall is level, the bonding force of the wallsoil interface and the upper overload effect $(\alpha=0, \beta=0, \delta=0$, $\left.c_{\mathrm{w}}=0, q=0\right)$ are not considered.

$$
N_{E}=\frac{1}{2} \gamma H^{2} K_{\mathrm{pl}}+c H K_{\mathrm{p} 3}
$$

Since the normal force $N_{\mathrm{E}}$ is a function of the slip angle $\theta$,

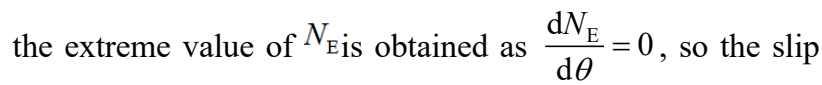
angle is $\theta_{\mathrm{p}}=\frac{\pi}{4}-\frac{\varphi}{2}$.

Substituting Eq. (11) to obtain the minimum value $N_{\text {Ep }}$ expression $(F=0)$, so the passive earth pressure is $E_{\mathrm{p}}=N_{\mathrm{Ep}}=\frac{1}{2} \gamma H^{2} K_{\mathrm{p}}+2 c H \sqrt{K_{\mathrm{p}}}$.

where, $K_{\mathrm{p}}=\tan ^{2}\left(\frac{\pi}{4}+\frac{\varphi}{2}\right)$.

When the back of the wall is vertical and smooth, the backfill is level, and there is no overload effect, the calculation formula of passive earth pressure is equal to the Rankine's passive earth pressure. 


\subsection{Active earth pressure}

When there is tension crack on the surface of filling soil (when it rotates around the top of the wall, it can not be considered), the crack depth $z_{0}$ is set as

$z_{0}=\frac{2 c}{\gamma} \sqrt{\frac{1+\sin \varphi}{1-\sin \varphi}}-\frac{q}{\gamma}$

When the strip uniform load has a certain distance from the top of the wall, $q=0$ can be taken. When $z_{0} \leq 0$, it means no crack development, then $z_{0}=0$. It can be seen from the formula that the crack depth at different positions of the fill is not the same under the action of non-uniform load. In order to simplify the analysis, $z_{0}$ at the top of the wall is approximately taken as the unified crack depth.

Considering the influence of the filling slope angle and wall back inclination angle, the reduced height $h_{0}$ is

$$
h_{0}=z_{0} \frac{\cos \alpha \cos \beta}{\cos (\alpha-\beta)}
$$

Then the wall height $h$ after deducting the crack depth is

$$
h=H-h_{0}
$$

In the same way, the active earth pressure calculation model is established as shown in Fig. 2.

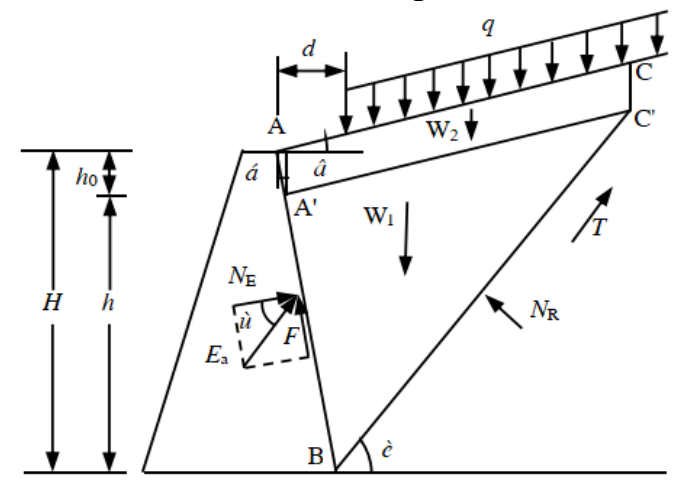

(a) Retaining wall conditions

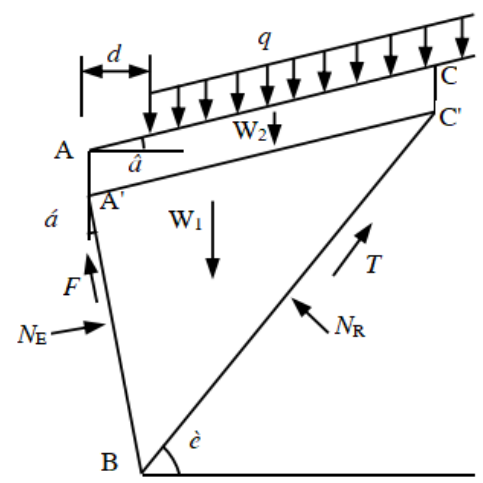

(b) Force on wedge

Fig. 2. Condition of retaining wall and forces on the wedge. $\mathrm{AB}$ is

The shearing force (tangential force) on the wall back

$$
F=\frac{c_{\mathrm{w}} h}{\cos \alpha}+N_{\mathrm{E}} \tan \delta
$$

The shearing force on the slip surface $\mathrm{BC}$ in the filling is

$$
T=\frac{c h \cos (\alpha-\beta)}{\cos \alpha \sin (\theta-\beta)}+N_{\mathrm{R}} \tan \varphi
$$

where, $F$ is the tangential force acting on the wall back, which is composed of the bonding and friction force of the wall-soil. $N_{\mathrm{E}}$ is the normal force acting on the wall back. $T$ is the tangential force acting on the slip surface, which is composed of the cohesion and friction of the filling. $N_{\mathrm{R}}$ is the normal force acting on the slip surface, $\delta$ is the friction angle of the wall and soil, $\varphi$ is the internal friction angle of the filling, and $q$ is the concentration of the projection of the overload on the horizontal plane. The meanings of other symbols are shown in Fig. 2.

For slip wedges, there are some relations as follows:

$$
\begin{gathered}
\overline{A^{\prime} B}=\frac{h}{\cos \alpha}, \overline{A^{\prime} C^{\prime}}=\frac{\overline{A^{\prime} B} \cos (\theta-\alpha)}{\sin (\theta-\beta)}=\frac{h \cos (\theta-\alpha)}{\cos \alpha \sin (\theta-\beta)}, \\
\overline{B C^{\prime}}=\frac{\overline{A^{\prime} B} \cos (\alpha-\beta)}{\sin (\theta-\beta)}=\frac{h \cos (\alpha-\beta)}{\cos \alpha \sin (\theta-\beta)} .
\end{gathered}
$$

The self-weight of the soil is:

$$
\begin{aligned}
W_{1} & =\frac{\gamma}{2} \overline{A^{\prime} B} * \overline{A^{\prime} C^{\prime}} \cos (\alpha-\beta) \\
& =\frac{1}{2} \gamma h^{2} \frac{\cos (\theta-\alpha) \cos (\alpha-\beta)}{\cos ^{2} \alpha \sin (\theta-\beta)} \\
W_{2} & =\gamma z_{0} * \overline{A^{\prime} C^{\prime}} \cos \beta \\
& =\gamma z_{0} h \frac{\cos (\theta-\alpha) \cos \beta}{\cos \alpha \sin (\theta-\beta)}
\end{aligned}
$$

The overload on the surface of filling is as follows:

$$
\begin{aligned}
Q & =q * \overline{A^{\prime} C^{\prime}} \cos \beta-q d \\
& =\frac{q h \cos (\theta-\alpha) \cos \beta}{\cos \alpha \sin (\theta-\beta)}-q d
\end{aligned}
$$

According to the force of the wedge, the equilibrium equations of $X$ and $Y$ forces are listed respectively, namely

$$
\begin{aligned}
\sum F_{\mathrm{y}}= & Q+W_{1}+W_{2}-F \cos \alpha-N_{\mathrm{E}} \sin \alpha \\
& -T \sin \theta-N_{\mathrm{R}} \cos \theta=0 \\
\sum F_{\mathrm{x}}= & -F \sin \alpha+N_{\mathrm{E}} \cos \alpha+T \cos \theta \\
& -N_{\mathrm{R}} \sin \theta=0
\end{aligned}
$$

Substituting Eqs. (12) to (19) into the balance Eqs. (20) and (21) to solve them simultaneously, eliminating $N_{\mathrm{R}}$, then get

$$
\begin{aligned}
N_{\mathrm{E}}= & \frac{1}{2} \gamma h^{2} K_{\mathrm{a} 1}+\left(\gamma z_{0}+q\right) h K_{\mathrm{a} 2}-c h K_{\mathrm{a} 3} \\
& -c_{w} h K_{\mathrm{a} 4}-q d K_{\mathrm{a} 5}
\end{aligned}
$$

where,

$K_{\mathrm{a} 1}=\frac{\cos (\theta-\alpha) \cos (\alpha-\beta) \sin (\theta-\varphi) \cos \delta}{\cos ^{2} \alpha \sin (\theta-\beta) \cos (\theta-\varphi-\alpha-\delta)}$,

$K_{\mathrm{a} 2}=\frac{\cos (\theta-\alpha) \cos \beta \sin (\theta-\varphi) \cos \delta}{\cos \alpha \sin (\theta-\beta) \cos (\theta-\varphi-\alpha-\delta)}, K_{\mathrm{a} 3}=\frac{\cos (\alpha-\beta) \cos \varphi \cos \delta}{\cos \alpha \sin (\theta-\beta) \cos (\theta-\varphi-\alpha-\delta)}$,

$K_{\mathrm{a} 4}=\frac{\sin (\theta-\varphi-\alpha) \cos \delta}{\cos \alpha \cos (\theta-\varphi-\alpha-\delta)}, \quad K_{\mathrm{a} 5}=\frac{\sin (\theta-\varphi) \cos \delta}{\cos (\theta-\varphi-\alpha-\delta)}$.

Since the normal force $N_{\mathrm{E}}$ is a function of the slip angle $\theta$ and there is a maximum value $N_{\mathrm{E}_{\mathrm{a}}}$, the active earth pressure $E_{\mathrm{a}}$ is 


$$
E_{\mathrm{a}}=\sqrt{F^{2}+N_{\mathrm{Ea}}^{2}}
$$

where, $N_{\mathrm{E}}$ in $F$ calculation formula is replaced by $N_{\mathrm{E}_{\mathrm{a}}}$. The angle between the direction of active earth pressure and the normal of the wall back is $\omega_{\mathrm{a}}$ :

$\omega_{\mathrm{a}}=\arctan \frac{F}{N_{\mathrm{Ea}}}=\arctan \frac{\frac{c_{\mathrm{w}} h}{\cos \alpha}+N_{\mathrm{Ea}} \tan \delta}{N_{\text {Ea }}}$

Obviously $\omega_{\mathrm{a}}>\delta$, and $\omega_{\mathrm{a}}$ changes with $c_{\mathrm{w}}$. However, when $c_{\mathrm{w}}=0, \omega_{\mathrm{a}}=\delta, E_{\mathrm{a}}=N_{\mathrm{E}_{\mathrm{a}}} / \cos \delta$. Assuming that the angle between the direction of the earth pressure and the normal direction of the wall is the friction angle of the wall and the soil, the calculated earth pressure is only the resultant force of the normal force and the friction, the effect of the bonding force of the wall-soil is not correctly considered.

When the filling behind the wall is cohesionless soil $\left(c=0, c_{\mathrm{w}}=0\right)$ and there is no overload effect $(q=0)$, the Eq. (22) is

$$
N_{\mathrm{E}}=\frac{1}{2} \gamma H^{2} K_{\mathrm{a} 1}
$$

Since the normal force $N_{\mathrm{E}}$ is a function of the slip angle $\theta$, the explicit expression of can be obtained directly through $\mathrm{d} N_{\mathrm{E}} / \mathrm{d} \theta=0$, and the expression of the maximum value $N_{\mathrm{E}_{\mathrm{a}}}$ can be obtained by substituting it into Eq. (25), and $F=N_{\mathrm{Ea}} \tan \delta$.

The active earth pressure is $E_{\mathrm{a}}=\sqrt{F^{2}+N_{\mathrm{Ea}}^{2}}=\frac{1}{2} \gamma H^{2} K_{\mathrm{a}}$.

$$
\text { where, } K_{\mathrm{a}}=\frac{\cos ^{2}(\varphi-\alpha)}{\cos ^{2} \alpha \cos (\alpha+\delta)\left[1+\sqrt{\frac{\sin (\varphi+\delta) \sin (\varphi-\beta)}{\cos (\alpha+\delta) \cos (\alpha-\beta)}}\right]^{2}} \text {. }
$$

If the filling behind the wall is cohesionless soil and there is no overload effect, the active earth pressure calculation formula is equal to the Coulomb's active earth pressure.

When the back of the wall is vertical and smooth, and the filling behind the wall is level, the bonding force of the wall-soil and the upper overload effect $\left(\alpha=0, \beta=0, \delta=0, c_{\mathrm{w}}=0\right.$, $q=0$ ) are not considered

$N_{\mathrm{E}}=\frac{1}{2} \gamma h^{2} K_{\mathrm{a} 1}+\gamma z_{0} h K_{\mathrm{a} 2}-c h K_{\mathrm{a} 3}$

Since the normal force $N_{\mathrm{E}}$ is a function of the slip angle $\theta$, the extreme value of the normal force $N_{\mathrm{E}}$ can be obtaimed as $\frac{\mathrm{d} N_{\mathrm{E}}}{\mathrm{d} \theta}=0$. The slip angle is $\theta_{\mathrm{a}}=\frac{\pi}{4}+\frac{\varphi}{2}$.

Substituting the slip angle $\theta_{\mathrm{a}}$ into Eq. (26) to obtain the maximum value $N_{\mathrm{E}_{\mathrm{a}}}$ expression $(F=0)$, the active earth

$$
\text { pressure is } \begin{aligned}
E_{\mathrm{a}}=N_{\mathrm{E}_{\mathrm{a}}} & =\frac{1}{2} \gamma h^{2} K_{\mathrm{a}}+\gamma z_{0} h K_{\mathrm{a}}-2 c h \sqrt{K_{\mathrm{a}}} \\
& =\frac{1}{2} \gamma H^{2} K_{\mathrm{a}}-2 c H \sqrt{K_{\mathrm{a}}}+\frac{2 c^{2}}{\gamma}
\end{aligned}
$$

where, $K_{\mathrm{a}}=\tan ^{2}\left(\frac{\pi}{4}-\frac{\varphi}{2}\right)$.
If the filling behind the wall is cohesive soil and there is no overload effect, the active earth pressure calculation formula is equal to the Rankine's active earth pressure.

\section{Results and discussion}

\subsection{Comparative analysis based on examples}

Example 1: The height of a retaining wall is $H=10 \mathrm{~m}, \gamma=18.6$ $\mathrm{kN} / \mathrm{m}^{3}, \varphi=24^{\circ}$, and there is no overload on the filling surface. Other relevant parameters and calculation results are shown in Table 1.

Example 2: The height of a retaining wall is $H=8 \mathrm{~m}$, $\gamma=18.6 \mathrm{kN} / \mathrm{m}^{3}, \varphi=20^{\circ}$, and the filling surface is uniformly overloaded $q=10 \mathrm{kN} / \mathrm{m}$. Other relevant parameters and calculation results are listed in Table 2.

According to Table 1, for the conditions that meet Rankine's assumptions, the calculation results of the proposed method are the same as those of Rankine's formula. For the conditions that meet the assumptions of Coulomb's theory, the calculation results of the proposed method are the same as those of Coulomb's formula. For the general form of cohesive soil retaining wall, if the bonding force of the wall-soil is not taken into account, considering the influence of the inclination of the wall and the slope angle of the filling, the tensile cracking depth of the surface soil is reduced. Therefore, the results of the proposed method are larger, but it should be more reasonable. When considering the bonding force of the wall-soil interface, the results calculated in this study are larger than those calculated by others.

Table 1. Parameters and calculated results of example of active earth pressure.

\begin{tabular}{c|c|c|c|c|c|c|c|c|c}
\hline $\boldsymbol{\alpha}$ & $\boldsymbol{\beta}$ & $\boldsymbol{\delta}$ & $\boldsymbol{c}$ & $\boldsymbol{c}_{\mathrm{w}}$ & \multicolumn{5}{|c}{$E_{\mathrm{a}(\mathbf{k N} / \mathbf{m})}$} \\
\cline { 5 - 8 }$\left({ }^{\circ}\right)$ & $\left.\mathbf{(}^{\circ}\right)$ & $\left.\boldsymbol{(}^{\circ}\right)$ & $(\mathbf{k P a})$ & $(\mathbf{k P a})$ & $\mathbf{L u}^{[13]}$ & $\mathbf{H u}^{[13]}$ & Rankine & Coulomb & $\begin{array}{c}\text { Proposed } \\
\text { Method }\end{array}$ \\
\hline 0 & 0 & 0 & 0 & 0 & 392.2 & 392.2 & 392.2 & 392.2 & 392.2 \\
0 & 0 & 0 & 10 & 0 & 273.1 & 273.1 & 273.1 & & 273.1 \\
5 & 5 & 5 & 0 & 0 & 433.8 & 433.8 & & 433.8 & 433.8 \\
5 & 5 & 15 & 0 & 0 & 414.3 & 414.3 & & 414.3 & 414.3 \\
5 & 10 & 10 & 10 & 0 & 328.4 & 328.4 & & & 330.3 \\
5 & 10 & 10 & 10 & 5 & 310.4 & 310.4 & & & 322.3 \\
5 & 10 & 10 & 10 & 10 & 293.5 & 293.5 & & & 320.8 \\
10 & 10 & 15 & 10 & 0 & 368.8 & 368.8 & & & 373.1 \\
\hline
\end{tabular}

According to Table 2, for the conditions that meet the Rankine's assumptions, the calculation results of the proposed method are the same as those of the Rankine's formula. For retaining walls that meet the assumptions of Coulomb's theory and the ground level, the calculation results of the proposed method are the same as those of the Coulomb's formula. For the case of the ground is inclined, the calculation results of the proposed method are the same as the previous methods, and the difference between the calculation results of the Coulomb's algorithm is less than $0.1 \%$. The reason for the error is that the ground overload is converted into the thickness of the soil layer when applying Coulomb's theory, but the proposed method does not have this conversion. For the general form of cohesive soil retaining wall, if the bonding force of the wall-soil is not considered, the results of the proposed method are consistent with those obtained by others. When the bonding force of 
the wall-soil interface is considered, the solution calculated in this study is larger than that of others.

Table 2. Parameters and calculated results of example of passive earth pressure.

\begin{tabular}{c|c|c|c|c|c|c|c|c}
\hline & $\beta$ & $\delta$ & $c$ & $c_{\mathrm{w}}$ \\
$\left({ }^{\circ}\right)$ & $\left(^{\circ}\right)$ & $\left(^{\circ}\right)$ & $(\mathrm{kPa})$ & $(\mathrm{kPa})$ & $\mathrm{Hu}^{[14]}$ & Rankine & Coulomb & $\begin{array}{c}\text { Proposed } \\
\text { Method }\end{array}$ \\
\hline 0 & 0 & 0 & 0 & 0 & 1377.1 & 1377.1 & 1377.1 & 1377.1 \\
0 & 0 & 0 & 10 & 0 & 1605.6 & 1605.6 & & 1605.6 \\
5 & 5 & 5 & 0 & 0 & 1675.1 & & 1676.4 & 1675.1 \\
5 & 5 & 15 & 0 & 0 & 2233.4 & & 2235.1 & 2233.4 \\
5 & 10 & 10 & 20 & 0 & 2963.1 & & & 2963.1 \\
5 & 10 & 10 & 20 & 5 & 3030.5 & & & 3037.7 \\
5 & 10 & 10 & 20 & 10 & 3097.9 & & & 3112.2 \\
5 & 10 & 10 & 20 & 15 & 3162.7 & & & 3185.8 \\
\hline
\end{tabular}

\subsection{The influence of the bonding force of the wall-soil} interface

The height of the retaining wall $H=10 \mathrm{~m}$, the filling $\gamma=18.6 \mathrm{kN} / \mathrm{m}^{3}, \varphi=24^{\circ}, \boldsymbol{\alpha}=10^{\circ}$, the inclination angle of filling surface $\beta=20^{\circ}$, and the wall-soil friction angle $\delta=15^{\circ}$. For the above example, take $q=20 \mathrm{kPa}, d=0$, take $c=0,5$, $10,15,20,25,30,35,40 \mathrm{kPa}, c_{\mathrm{w}}=(0-0.8) c$ to study and analyze the influence of $c$ and $c_{\mathrm{w}}$ (Figs. 3 to 5).

Figs. 3(a) and 3(b) respectively reflect the changes of active and passive earth pressure acting on the back of the retaining wall with $c_{\mathrm{w}}$ and $c$. For active earth pressure, when $c \geq 15 \mathrm{kPa}$, the active earth pressure first decreases and then increases with the increase of $c_{\mathrm{w}}$ and $c_{\mathrm{w}}{ }^{\prime} c$. When $c<15 \mathrm{kPa}$, the active earth pressure increases with the increase of $c_{\mathrm{w}}$ and $c_{\mathrm{w}} / c$; The active earth pressure decreases with the increase of $c$, and the rate of decrease is gradually slowing down. The passive earth pressure increases with the increase of $c_{\mathrm{w}}, c$, and $c_{\mathrm{w}}{ }^{\prime} c$. The active earth pressure keeps increasing with the increase of $c_{\mathrm{w}}$ value, but the overall change is small. The effect of $c$ on active earth pressure and passive earth pressure is more significant than $c_{\mathrm{w}}$

Figs. 4(a) and 4(b) respectively reflect the changes of the active and passive slip angle of the filling behind the retaining wall with $c_{\mathrm{w}}$ and $c$. For the active slip angle $\theta_{\mathrm{a}}, \theta_{\mathrm{a}}$ decreases with the increase of $c_{\mathrm{w}}$ and $c_{\mathrm{w}} / c$, but the overall change is small; $\theta_{\mathrm{a}}$ increases with the increase of $c$, and the increasing speed is gradually slowing down. For the passive slip angle $\theta_{\mathrm{p}}, \theta_{\mathrm{p}}$ continuously decreases with the increase of $c, c_{\mathrm{w}}$, and $c_{\mathrm{w}}{ }^{\prime} c$. The influence of $c$ on active and passive slip angle is more significant than $c_{\mathrm{w}^{\prime}}$

Figs. 5(a) and 5(b) respectively reflect the changes of the angle among the active earth pressure and the passive earth pressure and the back normal of the retaining wall with $c_{\mathrm{w}}$ and $c$. The angle between the earth pressure and the normal of the wall back $\omega_{\mathrm{a}}, \omega_{\mathrm{p}}$ increase continuously with the increase of $c_{\mathrm{w}}, c_{\mathrm{w}}{ }^{\prime} c$ and $c$. Among them, the overall change of $\omega_{\mathrm{p}}$ with the change of $c_{\mathrm{w}}$ is small, and the change of $\omega_{\mathrm{a}}$ with the change of $c_{\mathrm{w}}$ is significant. The influence of $c$ value on the angle between the earth pressure and the normal line of the wall back is more significant than that of $c_{\mathrm{w}}$.

Figs. 5(a) and 5(b) respectively reflect the changes of the angle among the active earth pressure and the passive earth pressure and the back normal of the retaining wall with $c_{\mathrm{w}}$ and $c$. The angle between the earth pressure and the normal of the wall back $\omega_{\mathrm{a}}, \omega_{\mathrm{p}}$ increase continuously with the increase of $c_{\mathrm{w}}, c_{\mathrm{w}}{ }^{\prime} c$ and $c$. Among them, the overall change of $\omega_{\mathrm{p}}$ with the change of $c_{\mathrm{w}}$ is small, and the change of $\omega_{\mathrm{a}}$ with the change of $c_{\mathrm{w}}$ is significant. The influence of $c$ value on the angle between the earth pressure and the normal line of the wall back is more significant than that of $c_{\mathrm{w}}$.

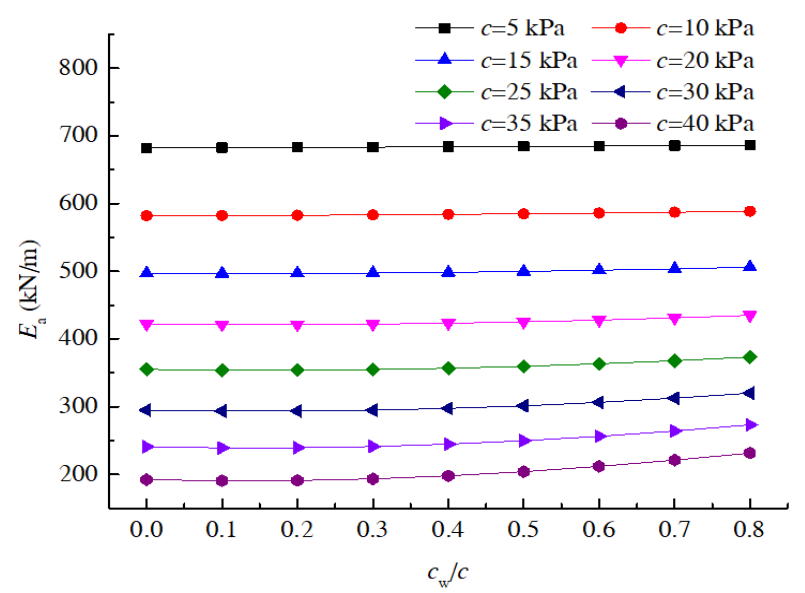

(a) Active earth pressure

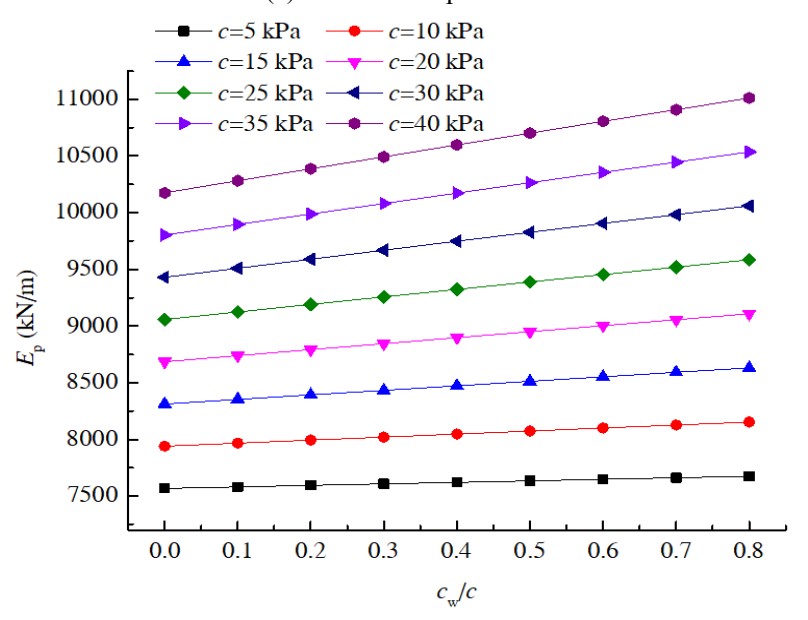

(b) Passive earth pressure

Fig. 3. Change of active and passive earth pressures with $c_{\mathrm{w}}{ }^{\prime} c$.

The analysis is based on the above examples and the calculation results. As seen from Figs. 3 to $5, c_{\mathrm{w}}$ not only changes the resultant force and direction of earth pressure, but also changes the slip angle. When $c \geq 15 \mathrm{kPa}$, the active earth pressure first decreases and then increases with the increase of $c_{\mathrm{w}}$; when $c<15 \mathrm{kPa}$, the active earth pressure increases with the increase of $c_{\mathrm{w}}$; the passive earth pressure increases continuously with the increase of $c_{\mathrm{w}}$. With the increase of the wall-soil interface bonding force $c_{\mathrm{w}}$, the active slip angle and the passive slip angle continue to decrease, and the angle between the earth pressure and the normal to the back of the wall increases.

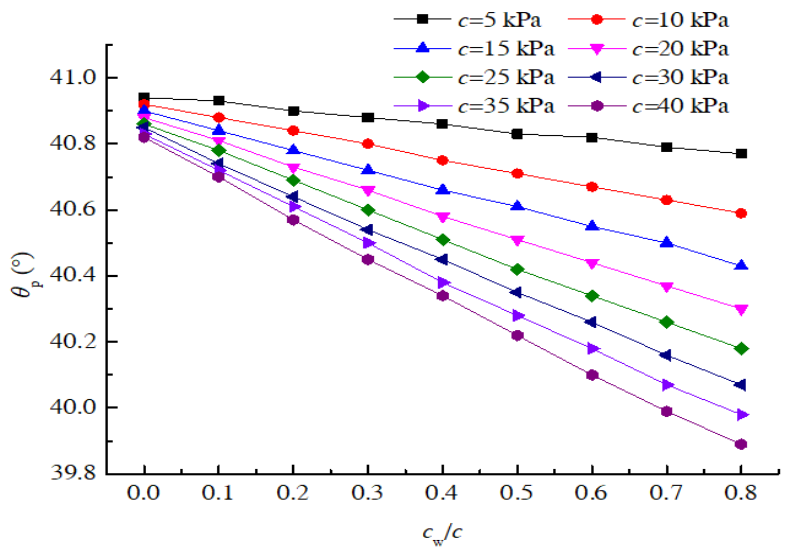

(a) Active slip angle 


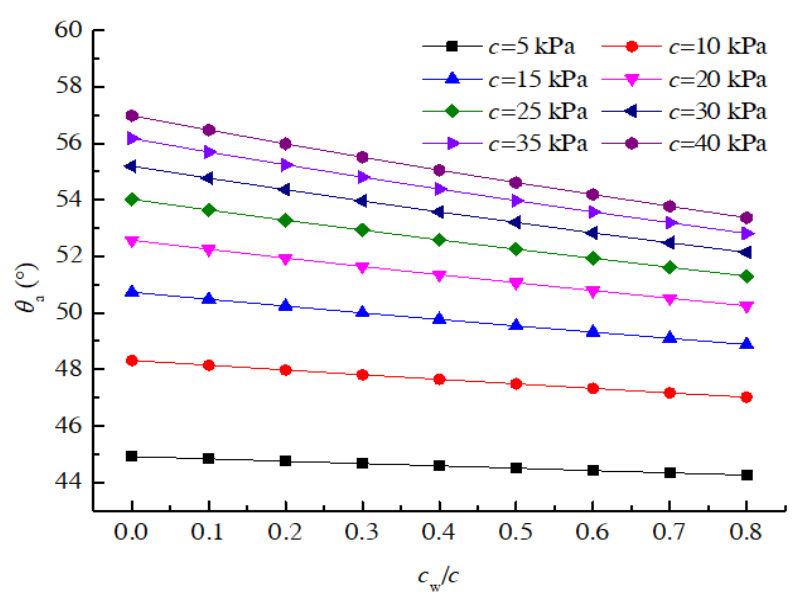

(b) Passive slip angle

Fig. 4. Change of active and passive slip angles with $c_{\mathrm{w}}{ }^{\prime} c$.

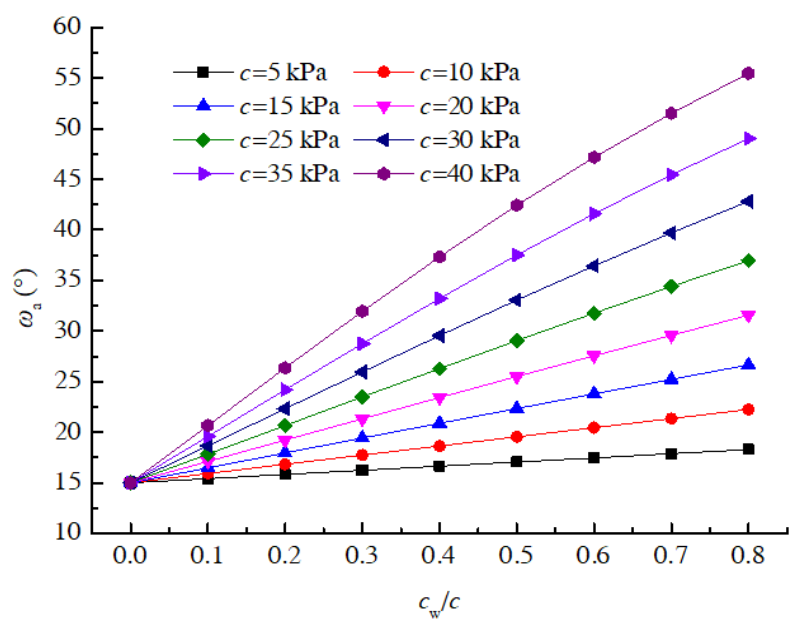

(a) $\omega_{\mathrm{a}}$

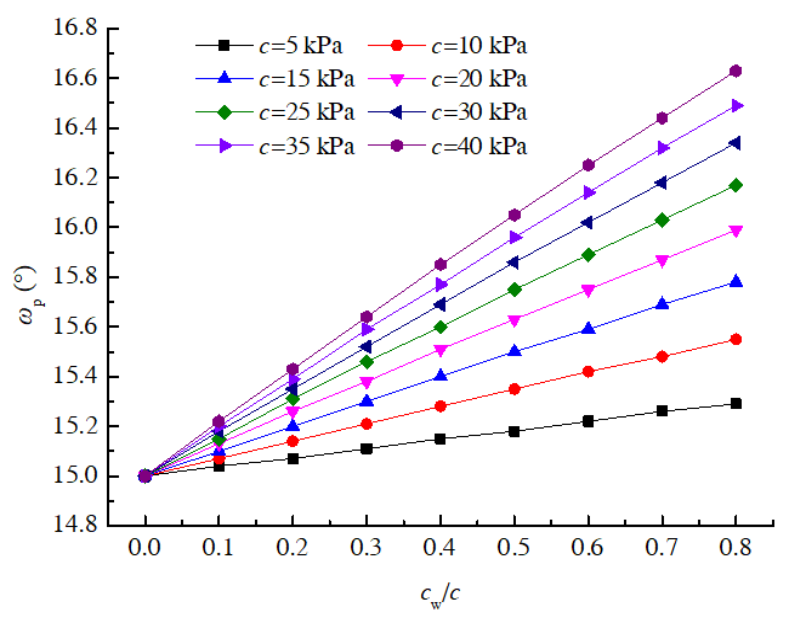

(b) $\omega_{\mathrm{p}}$

Fig. 5. Change of $\omega_{\mathrm{a}}$ and $\omega_{\mathrm{p}}$ with $c_{\mathrm{w}}{ }^{\prime} c$.

\subsection{The influence of load distance}

For the above calculation example, take $c=30 \mathrm{kPa}, c_{\mathrm{w}}=12$ $\mathrm{kPa}$, wall-soil friction angle $\delta=15^{\circ}, q=5,10,15,20 \mathrm{kPa}$ take $d=0,1,2,3,4,5,6,7,8 \mathrm{~m}$ to conduct research to analyze the influence of $q$ and $d$ (Figs. 6 to 8).

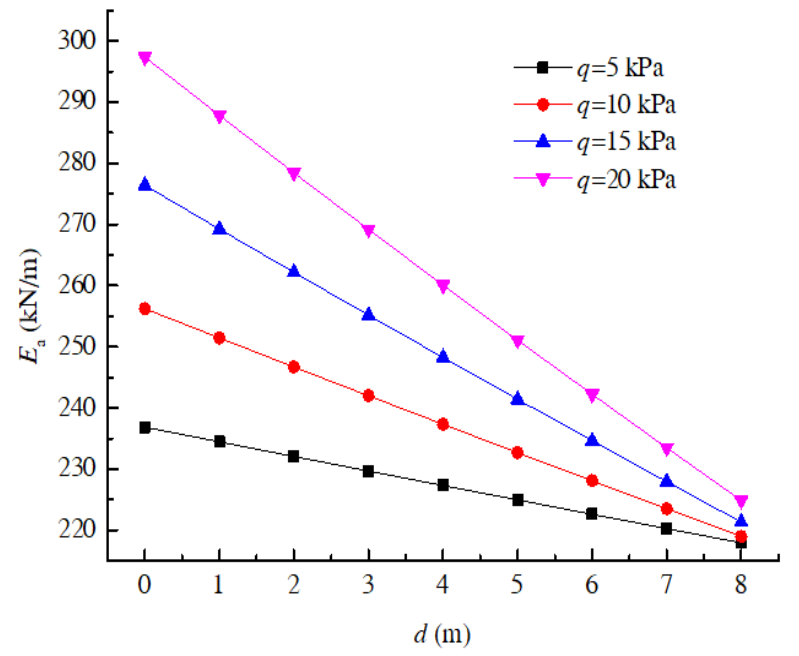

(a) Active earth pressure

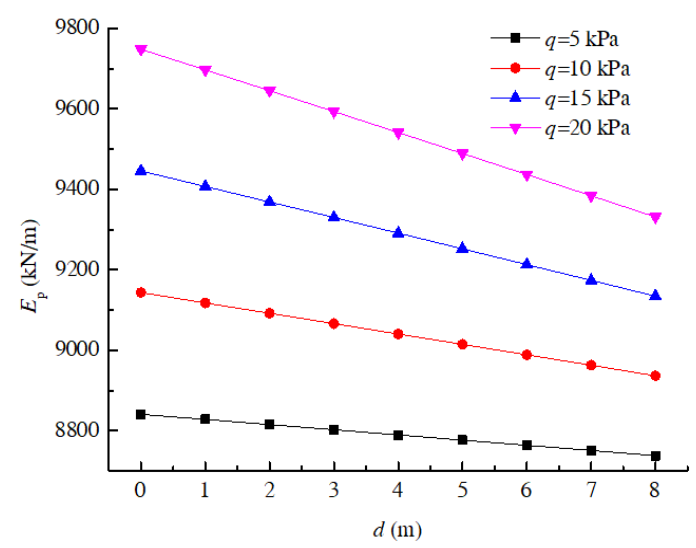

(b) Passive earth pressure

Fig. 6. Change of active and passive earth pressures with $d$.

Figs. 6(a) and 6(b) respectively reflect the change of active and passive earth pressure acting on the back of retaining wall with uniform load $q$ and action distance $d$ : when $q$ is constant, the active and passive earth pressures decrease with the increase of $d$; When $d$ is constant, the active and passive earth pressures increase with the increase of $q$.

Figs. 7(a) and 7(b) respectively reflect the changes of the active and passive slip angles acting on the back of the retaining wall with $q$ and $d$ : The active slip angle decreases with the increase of $q$ and $d$. While the passive slip angle increases with the increase of $q$ and $d$.

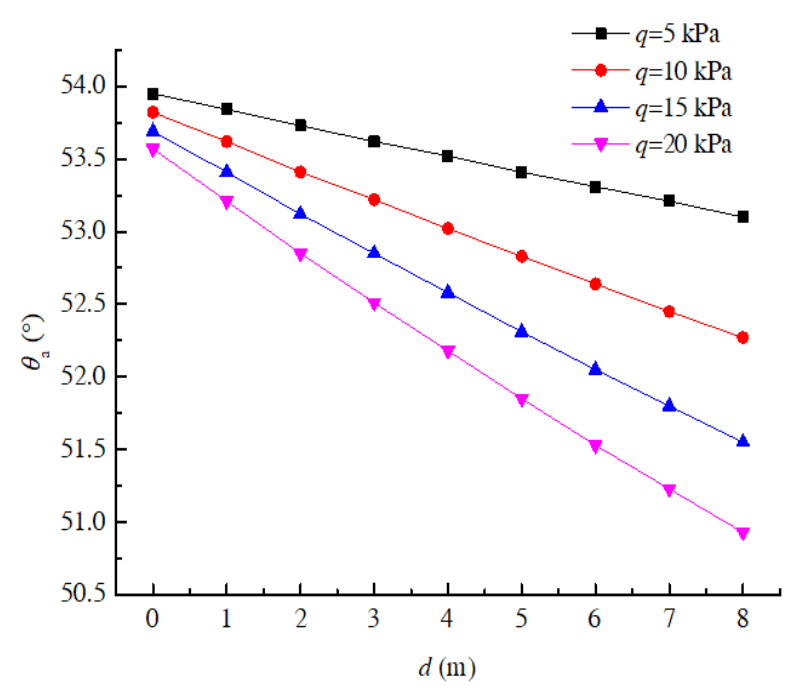


(a) Active slip angle

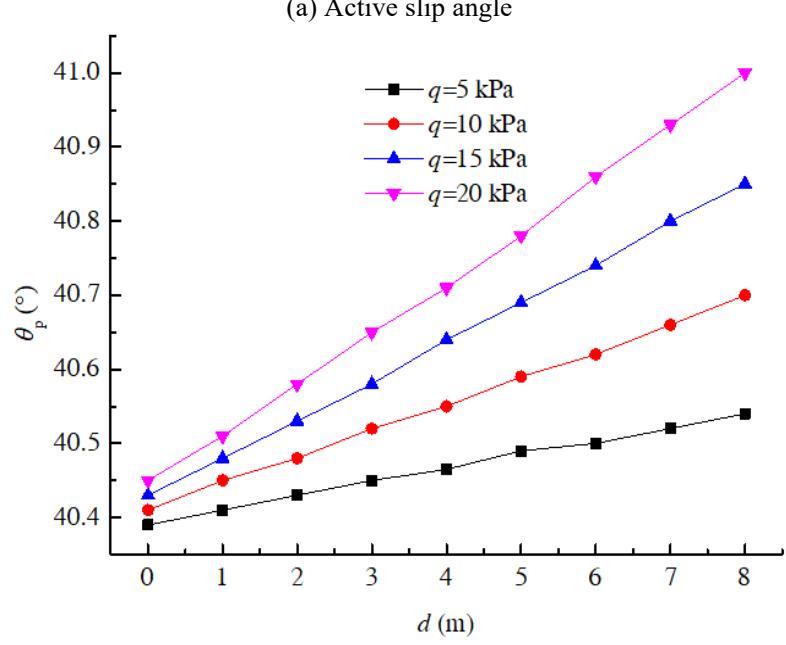

(b) Passive slip angle

Fig. 7. Change of active and passive slip angles with $d$.

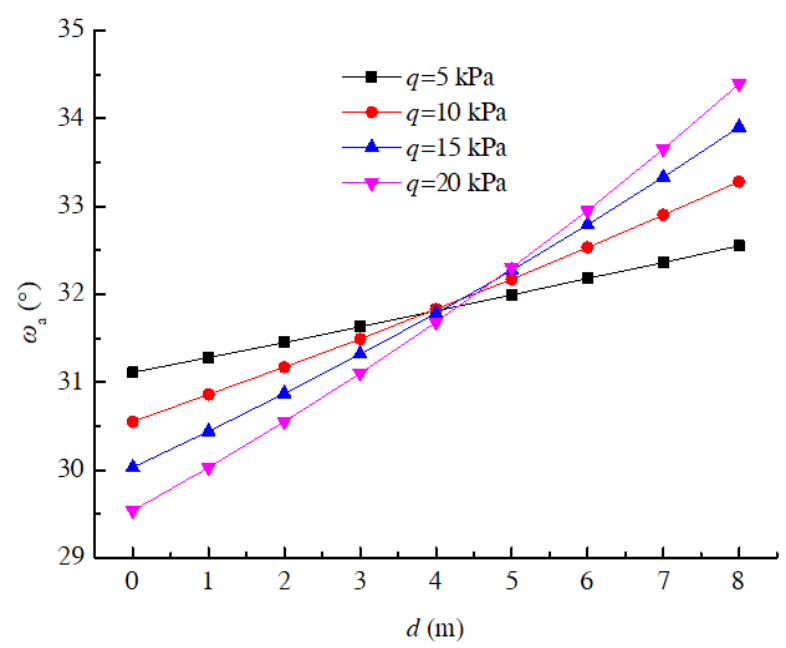

(a) $\omega_{\mathrm{a}}$

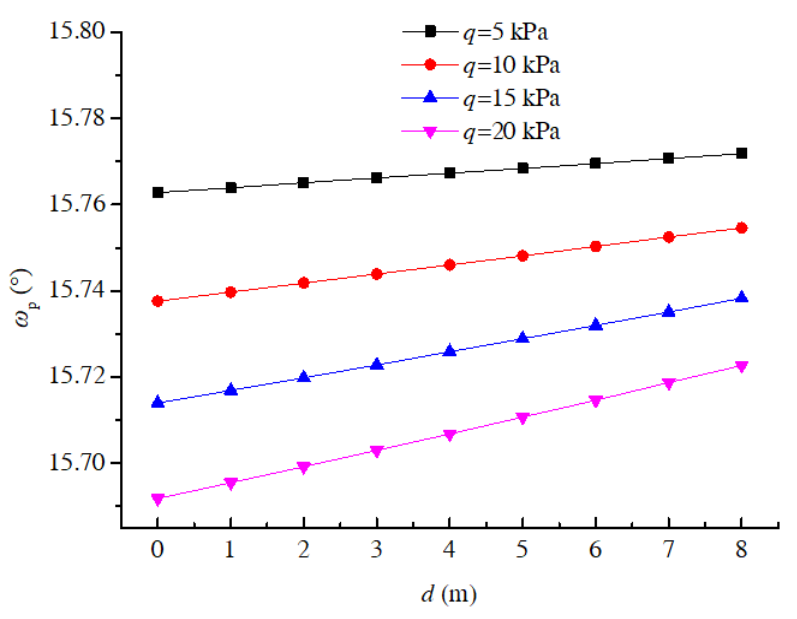

(b) $\omega_{\mathrm{p}}$

Fig. 8. Change of $\omega_{\mathrm{a}}$ and $\omega_{\mathrm{p}}$ with $d$.

Figs. 8(a) and 8(b) respectively reflect the change of the angle between the active and passive earth pressure acting on the back of retaining wall and the normal of the back of retaining wall with $q$ and $d$ : The angles $\omega_{\mathrm{a}}$ and $\omega_{\mathrm{p}}$ between the earth pressure and the normal of the wall back increase with the increase of $d$; when $d<4.5 \mathrm{~m}, \omega_{\text {a decreases with the }}$ increase of $q$; when $d>4.5 \mathrm{~m}, \omega_{\mathrm{a}}$ increases with the increase of $q ; \omega_{\mathrm{p}}$ decreases with the increase of $q$.

It can be seen from Figs. 6 to 8 that $d$ not only changes the resultant force and direction of earth pressure, but also changes the slip angle. The active and passive earth pressures decreases with the increase of $d$. With the increase of $d$, the active slip angle decreases and the passive slip angle increase. The angle among the active and passive earth pressure and the normal of the wall back increase with the increase of $d$.

\section{Conclusions}

To reveal the interaction between the retaining wall and the filling behind the wall, the direction of resultant force of earth pressure was not limited and the correlation of wall-soil mechanical parameters was not specified. The unified solution of extended Coulomb's earth pressure under complex conditions was established. Through the comparison between the calculation example and the existing algorithm, the main conclusions are obtained.

(1) Both the classic Coulomb's earth pressure and the Rankine's earth pressure are special cases of the new method. Limiting that the angle between the direction of the earth pressure the normal direction of the wall is the friction angle of the wall and soil, which will cause the wall-soil bonding force not be included in the resultant earth pressure, and the calculated result of the earth pressure is not correct.

(2) $c$ and $c_{\mathrm{w}}$ not only change the magnitude and direction of earth pressure, but also change the slip angle. The active earth pressure decreases with the increase of $c$. The passive earth pressure increases with the increase of $c_{\mathrm{w}}$ and c. The direction angle of action of active and passive earth pressure increases with the increase of $c$ and $c_{\mathrm{w}}$. The influence of $c$ on earth pressure is more significant than that of $c_{\mathrm{w}}$.

(3) $d$ and $q$ not only affect the magnitude and direction of the earth pressure, but also change the slip angle. The active and passive earth pressure decrease with the increase of $d$, and increase with the increase of $q$. When $d$ is small, the direction angle of active earth pressure decreases with the increase of $q$. When $d$ is large, the direction angle of active earth pressure increases with the increase of $q$.

Since the new method is only applicable to the calculation of earth pressure on static retaining walls, without considering the seismic effect. So the related content needed to be studied considering the seismic effect in the future.

\section{Acknowledgements}

The authors are grateful for the support provided by the National Natural Science Foundation-Shanxi Joint Fund Key Project (U1810203) and the Doctoral Fund Project of Henan Polytechnic University (648198).

This is an Open Access article distributed under the terms of the Creative Commons Attribution License. 


\section{References}

1. Motta, E., "Generalized Coulomb active earth pressure for distance surcharge". Journal of Geotechnical Engineering, 120(6), 1994, pp. $1072-1079$

2. Paik, K. H., Salgado, R., "Estimation of active earth pressure against rigid retaining walls considering arching effects". Geótechnique, 53(7) , 2003, pp. 643-653.

3. Khosravi, M. H., Pipatpongsa, T., Takemura, J, "Theoretical analysis of earth pressure against rigid retaining walls under translation mode". Soils and Foundations, 56(4), 2016, pp. 664-675.

4. Khosravi, M. H., Kargar, A. R., Amini, M., "Active earth pressures for non-planar to planar slip surfaces considering soil arching". International Journal of Geotechnical Engineering, 14(7), 2020, pp. 730-739.

5. Choudhury, D., Nimbalkar, S., "Seismic passive resistance by pseudo-dynamic method". Geótechnique, 55(9), 2005, pp. 699-702.

6. Ghosh, S., Sharma, R. P., "Seismic active earth pressure on the back of battered retaining wall supporting inclined backfill". International Journal of Geomechanics, 12(1), 2012, pp. 54.

7. Pain, A., Choudhury, D., Bhattacharyya, S.K., "Seismic stability of retaining wall-soil sliding interaction using modified pseudodynamic method". GéotechniqueLetteres, 5 (1), 2015, pp. 56-61.

8. Pain, A., Chen, Q. S., Nimbalkar, S., Zhou, Y. T., "Evaluation of seismic passive earth pressure of inclined rigid retaining wall considering soil arching effect". Soil Dynamics and Earthquake Engineering, 100, 2017, pp. 286-295.

9. Rajesh, B. G., Choudhury, D., "Generalized seismic active thrust on a retaining wall with submerged backfill using a modified pseudodynamic method". International Journal of Geomechanics, 17(3), 2017, pp. ID 06016023

10. Santhoshkumar, G., Ghosh, P., "Seismic passive earth pressure on an inclined cantilever retaining wall using method of stress characteristics-A new approach". Soil Dynamics and Earthquake Engineering, 107, 2018, pp. 77-82

11. Santhoshkumar, G., Ghosh, P., "Closed-form solution for seismic earth pressure on bilinear retaining wall using method of characteristics". Journal of Earthquake Engineering. 25(6), 2021, pp. 1171-1190.

12. Barabash, M. S., Pisarevskyi, B. Y., Bashynskyi, Y., “ATaking into account material damping in seismic analysis of structures". Technical Journal, 14(1), 2020, pp. 55-59.

13. Wang, S. R., Shi, K. P., Zhou, T. H., Zou, Y. F., Hu, J. C., "Foundation adaptability and subgrade deformation analysis of high-speed railway above the mined-out areas". Journal of Engineering Science and Technology Review, 14(1), 2021, pp. 170177.
14. Khatri, V. N., "Determination of passive earth pressure with lower bound finite elements limit analysis and modified pseudo-dynamic method". Geomechanics and Geoengineering, 14(3), 2019, pp. 218229.

15.Maskar, A., Madhekar, S., "Seismic earth pressure computation using modified Dubrova's model". Journal of GeoEngineering, 14(2), 2019, pp. 53-64.

16. Krabbenhoft, K., "Static and seismic earth pressure coefficients for vertical walls with horizontal backfill". Soil Dynamics and Earthquake Engineering, 104, 2018, pp. 403-407.

17. Gupta, A., Sawant V. A., "Effect of soil amplification on seismic earth pressure using pseudo-dynamic approach". International Journal of Geotechnical Engineering, 15(1), 2021, pp. 40-51.

18. Veiskarami, M., Chenari, R. J., Jameei, A. A., "A study on the static and seismic earth pressure problems in anisotropic granular media”. Geotechnical and Geological Engineering, 37, 2019, pp. 1987-2005.

19. Shukla, S. K., Gupta, S. K., Sivakugan, N., “Active earth pressure on retaining wall for $\mathrm{c}-\varphi$ soil backfill under seismic loading condition". Journal of Geotechnical and Geoenvironmental Engineering, 135(5), 2009, pp. 690-696.

20. Vahedifard, F., Leshchinsky, B. A., Mortezaei, K., Lu, N., "Active earth pressures for unsaturated retaining structures". Journal of Geotechnical and Geoenvironmental Engineering, 141(11), 2015, pp. 1-11.

21. Shukla, S. K., "Dynamic active thrust from c- $\varphi$ soil backfills". Soil Dynamics and Earthquake Engineering, 31(3), 2011, pp. 526529.

22. Peng, J. G., Zhu, Y. P., "Simplified method for calculating active earth pressure against rigid retaining walls for cohesive backfill". Soil Mechanics and Foundation Engineering, 55(6), 2019, pp. 374379.

23. Irdmoosa, K. G., Shahir, H., “Analytical solution for active earth pressure of $\mathrm{c}-\varphi$ soil considering arching effect". Geomechanics \& Geoengineering, 14(2), 2019, pp. 71-84.

24. Wang, S. R.,Li, N., Li, C. L., Zou, Z. S., Chang, X., "Instability mechanism analysis of pressure-arch in coal mining field under different seam dip angles". Dyna, 90(3), 2015, pp. 279-284.

25. Irdmoosa, K. G., Shahir H., "Analytical solution for passive earth pressure of $\mathrm{c}-\varphi$ soil using principal stress rotation assumption". Journal of GeoEngineering, 14(1), 2019, pp. 31-39. 